\title{
Different Relationship Between Anthropometric Markers and Umbilical Cord Plasma Leptin in Asian and Caucasian Neonates
}

\author{
LOUISA P.K. YEUNG, ALFRED C.K. WONG, XIAOHUI WANG, CARL L. BIRMINGHAM, \\ SABRINA LEWICKA, AND JEAN-PIERRE CHANOINE
}

\begin{abstract}
Endocrinology and Diabetes Unit, British Columbia's Children's Hospital, Vancouver BC V6H 3V4, Canada [L.P.K.Y., A.C.K.W., X.W., J.-P. C.]; Eating Disorders Clinic, St-Paul's Hospital, Vancouver BC V6Z 1Y6, Canada [C.L.B.]; Department of Pharmacology, University of Heidelberg, 69120 Heidelberg,
\end{abstract} Germany [S.L.]

\begin{abstract}
The leptin to fat ratio early in life could contribute to fixing the set point of leptin feedback at the hypothalamic level. Subjects from Asian and Caucasian ethnicities differ in body composition. We tested the hypothesis that anthropometric markers and their relationship to umbilical cord leptin, cortisol and cortisone, DHEAs and oestriol differed between Caucasians and Asians at birth. Birthweight, length, arm, calf and abdominal circumferences, scapular, triceps, quadriceps and abdominal skinfolds were measured in 180 healthy, full-term newborns of Asian and Caucasian ethnicities. Leptin and steroid hormone concentrations were determined in umbilical cord plasma. There was a significant difference in the slope of the regression between leptin and birthweight $(p=0.03)$ and calf circumference $(p=$ 0.05 ) between male Caucasian and Asian neonates. In contrast, in female neonates, there was no significant difference $(p=0.099$ and $p=0.07$ for birthweight and calf circumference, respectively). In addition, while the slopes of the regression plots were not
\end{abstract}

\section{ABSTRACT}

affected by gender in Asian newborns, there was a significant difference between male and female Caucasian newborns $(p=$ 0.006 and $p=0.002$ for birthweight and calf circumference, respectively). There was no significant correlation between cord leptin concentrations or anthropometric markers and steroid hormone concentrations. In conclusion, gender and ethnic differences in the relationship between leptin and anthropometric markers are detectable at birth between Asians and Caucasians, two ethnic groups that have been demonstrated to have different body compositions later in life. This may represent the first clinical evidence of a difference in leptin regulation between these two ethnic groups. (Pediatr Res 53: 1019-1024, 2003)

\author{
Abbreviations \\ BMI, body mass index \\ DHEAs, dehydroepiandrosterone sulfate
}

Leptin is a protein secreted mainly by the adipocyte in proportion to fat mass (1). An important role for leptin in humans is to inform the hypothalamus about the status of body-fat stores (2). Accordingly, a good correlation between leptin and body weight or fat mass has been repeatedly observed in adults (3) and infants (4-10). However, there is a wide dispersion in leptin concentrations for a given fat mass suggesting a variability in the relationship between leptin and body fat. The cause of this variability is largely unknown.

It has been suggested that programming of the hypothalamic regulatory mechanisms may play a role in the regulation of body fatness in adulthood (11-12) and Singhal et al. (13) recently postulated that early determinants of the leptin to fat

September 12, 2002; January 8, 2003.

Correspondence: Jean-Pierre Chanoine, M.D., Clinical Professor and Head, Endocrinology and Diabetes Unit, Room K4-212, British Columbia's Children's Hospital, 4480 Oak Street, Vancouver BC V6H 3V4 Canada; e-mail: jchanoine@cw.bc.ca

DOI: 10.1203/01.PDR.0000067140.75177.ED ratio could contribute to fixing the set point of leptin feedback at the hypothalamic level. A better understanding of the factors driving the relationship between leptin and body composition early in life is, therefore, important.

A potential source of variation in serum leptin concentrations is body-fat distribution (14-15). Differences in body fat distribution have been identified between subjects from different ethnicities, including between Asians and Caucasians. Deurenberg et al. (16) found that for a given body mass index (BMI), adults from Caucasian ethnicity had a lower percentage of body fat compared with adults from Chinese ethnicity. Wang et al. (17) observed that healthy Asian adults have lower BMIs but a higher percent of body fat compared with Caucasian subjects. Malina et al. (18) observed that Asian adolescent girls had more trunk s.c. adipose tissue compared with Caucasians. Recently, He et al. (19) showed that a decrease in the extremity skinfold thickness was already evident during the prepubertal period in Asian compared with Caucasian girls. 
Whether differences in body composition are present between Chinese and Caucasian subjects at birth or develop with time is unknown.

Another potential source of variability in leptin concentrations is the hormonal environment. For instance, the higher serum leptin concentrations observed in female compared with male subjects $(20)$ as early as during the neonatal period $(4,9)$ are not only explained by differences in body composition, but also by differences in sex steroids $(1,21)$. Cortisol is another steroid hormone that has been shown to increase leptin secretion in vitro and in vivo $(22,23)$. Of interest for the present study, a positive correlation between leptin and cortisol umbilical cord-blood concentrations has been reported by Maffeis et al. (9), raising the possibility that endogenous cortisol secretion could stimulate leptin secretion in the perinatal period.

We hypothesized that differences in body fat distribution are already present in Caucasian and Chinese neonates, and that the relationship between umbilical cord leptin concentrations and body composition is different in these two ethnic groups. The primary goal of the present study was to assess the relationship between leptin and height, weight and anthropometric measures of fat distribution in healthy neonates from Caucasian and Asian origin born in Vancouver, British Columbia. The secondary objective was to determine whether the umbilical cord concentrations of cortisol, cortisone, oestriol and DHEAs, which could potentially differ in Asian and Caucasian newborns, would explain some of the variability in neonatal leptin concentrations that we expected to find in Caucasian and Asian newborns.

\section{METHODS}

Subjects. We prospectively studied 180 healthy full-term newborns divided into four groups of 45 according to gender (male or female) and ethnicity (Caucasian or Asian). All newborns were born at Children's and Women's Hospital of British Columbia over a 6-month period and had both parents and all grandparents of the same ethnicity according to the information volunteered by the mother. "Caucasian" origin corresponds to Anglo-European descent. "Asian" origin refers to families of Chinese descent, mainly from Hong Kong, Taiwan or mainland China. The study was approved by the Ethics Committee of the University of British Columbia and written informed consent was obtained from all mothers after the study was explained to them by the examiner.

Demographic data. Maternal age and gestational age (calculated according to the date of the last menstrual period or, if unknown, to the ultrasound results) were obtained from the medical record. The mother was asked about her smoking and drinking habits, length of residence in Canada and was questioned about the highest education level she achieved and the present occupation of both parents. Data regarding parental education were collected as middle school, high school, college, university, and postuniversity as proposed by Duncan et al. (24). For analytical purposes, education was defined as presecondary or postsecondary. Occupational categories in- cluded operative, crafts, clerical (manual/nonmanual), service and manager.

Anthropometric characteristics. Birthweight and length were recorded at birth by the attending nurse. All other anthropometric determinations were performed within the first $24 \mathrm{~h}$ of life by a single examiner (L.P.K.Y). Scapular, quadriceps (mid-leg), triceps (mid-arm), and abdominal skinfolds were measured using a caliper (precision of 0.2 $\mathrm{mm}$ ). Mid-arm, mid-calf, and abdominal (at the umbilicus) circumferences were measured using a measuring tape (precision of $1 \mathrm{~mm}$ ). The intra-observer coefficient of variation was $0.5 \%$.

Venous cord plasma. Cord blood was collected from the umbilical vein on EDTA, kept at $4^{\circ} \mathrm{C}$ for one to twenty-four hours before being centrifuged and stored at $-80^{\circ} \mathrm{C}$. Leptin (Linco, St-Charles, MO, U.S.A.; intra- and inter-assay coefficients of variation [CV] $<7.5 \%$ and $<8.9 \%$, respectively) and dehydroepiandrosterone sulfate (DHEAs) (Diagnostic Products Corporation, Los Angeles, CA, U.S.A., intra- and interassay CV 4.4-5.3\% and 6.3-8.1\%) were measured by RIA (RIA) without extraction. Cortisone was measured by RIA after chloroform extraction as described by Weber et al. (25).

Unconjugated oestriol (intra- and inter-assay CV 1.8-2.5\% and 3.4-4.7\%, respectively) and cortisol (intra- and inter-assay $\mathrm{CV}<6.7 \%$ and $<7.9 \%$, respectively) concentrations were determined in simplicate by chemiluminescent immunoassay (Beckman Coulter, Fullerton, CA, U.S.A.).

Statistical methods. Values are expressed as mean $\pm \mathrm{SD}$, except when noted. Sample size was determined based on the ability to detect a 25\% difference in $r^{2}(r=$ relationship between cord leptin and birthweight in neonates of Caucasian and Asian ethnicities) with $\alpha=0.05$ and $\beta=0.80$, assuming an $r$ value of 0.50 for the correlation between birthweight and leptin concentrations $(4,5)$.

The differences in baseline characteristics (gestational age, maternal age, length of stay in Canada and time of examination) were examined in a two-way (ethnicity and gender) analysis of variance. The differences in anthropometric measures and cord plasma hormonal concentrations (after log transformation as appropriate) were examined using a two-way analysis of covariance, with socio-economic status of the parents and birthweight of the newborns as covariates where appropriate. The differences in parental education and occupation were analyzed by $\chi^{2}$ and Fisher's exact tests, respectively. A multiple linear regression model (using all 180 subjects) was used to investigate the nature of the relationship between cord plasma leptin concentrations and each of the anthropometric measures among the Caucasian and Asian female and male newborns, with logarithm of leptin as dependent variable, and anthropometric measures, ethnicity and gender as independent variables. Similarity of regression slopes among the subgroups was examined by the significance of the 3-way interaction between anthropometric measure, ethnicity and gender variables. Data were analyzed by using SAS software version 8.2 (SAS Institute Inc. Cary, NC, U.S.A.), with $p<0.05$ as the significance level. 


\section{RESULTS}

Demographic data. Table 1 describes the characteristics of the Caucasian and Asian neonates and their parents. There was no significant difference in maternal age and length of time after delivery that anthropometric measurements were performed. Gestational age was marginally but significantly smaller in Asian compared with Caucasian neonates. One Asian and eight Caucasian mothers smoked to some degree during pregnancy, and one mother in each ethnic group had drunk some alcohol during pregnancy. Removing these data from analysis did not influence the results.

In keeping with their recent history of immigration to British Columbia, length of stay in Canada was significantly shorter for Asian than for Caucasian parents $(p<0.0001)$. Asian fathers $(p=0.02)$ and mothers $(p=0.04)$ were significantly less likely to have received postsecondary education compared with their Caucasian counterparts. Accordingly, Caucasian fathers $(p=0.07)$ and mothers $(p<0.0001)$ had a higher employment level compared with their Asian counterparts, although the difference was only significant for mothers.

Anthropometric data. Table 2 describes the anthropometric characteristics of the four groups under study. Birthweight, length, arm circumference and triceps skinfold were all significantly affected by ethnicity, with Caucasian newborns having greater measurements than Asian newborns. Birthweight, length, arm circumference, and all skinfold determinations were significantly affected by gender, with male newborns having greater measures than female newborns. Abdomen circumference among the male newborns was found to be greater in Caucasian newborns $(p=0.004)$, but there was no evidence that the difference in ethnicity exists among the female newborns $(p=0.54)$. Similarly, within the Asian neonates, this measure was slightly greater in the male newborns $(p=0.02)$, but it was comparable between the male and female among the Caucasian newborns $(p=0.97)$.

Leptin and anthropometric data. Leptin concentrations were significantly higher in Asian and Caucasian female compared with male neonates, even after adjusting for birthweight (Table 3). Leptin concentrations were not affected by ethnicity.

The correlation between cord leptin concentration and anthropometric measures in each of the four sub-groups is presented in Table 4. To further investigate the effect of gender and ethnicity on the relationship between cord leptin concentration and each of the anthropometric measures, we fitted a multiple linear regression model and found that the relationship between leptin concentrations and several anthropometric determinations was significantly affected by gender and ethnicity. This was the case for the relationship between leptin and birthweight $(p=0.009)$ and calf circumference $(p=0.009)$. The slopes of the regressions were significantly different between Asians and Caucasians in male $(p=0.03$ and $p=0.05$ for birthweight and calf circumference, respectively) but not in female newborns ( $p=0.099$ and $p=0.07$ for birthweight and calf circumference, respectively). In addition, while the slopes

Table 1. Characteristics of the Asian and Caucasian neonates and their parents

\begin{tabular}{|c|c|c|c|c|c|}
\hline & \multicolumn{2}{|c|}{ Male } & \multicolumn{2}{|c|}{ Female } & \multirow[b]{2}{*}{ 2-way ANOVA } \\
\hline & Asian & Caucasian & Asian & Caucasian & \\
\hline Gestational age (wk) & $39.3(1.2)$ & $39.4(1.0)$ & $39.1(1.1)$ & $39.7(1.1)$ & Race $(p=0.03)$ \\
\hline Maternal age $(y)$ & $30.9(4.2)$ & $31.4(4.6)$ & $32.1(5.0)$ & $32.7(4.9)$ & NS \\
\hline Residence in Canada (y) & $11.2(10.4)$ & $27.8(9.6)$ & $10.1(9.1)$ & $27.9(12.4)$ & Race $(p<0.0001)$ \\
\hline Time of exam (h after birth) & $14.0(7.4)$ & $14.6(8.1)$ & $14.6(6.7)$ & $11.5(7.2)$ & $\mathrm{NS}$ \\
\hline Mean (SD) & & & & & \\
\hline
\end{tabular}

Table 2. Anthropometric measurements of the Asian and Caucasian newborns

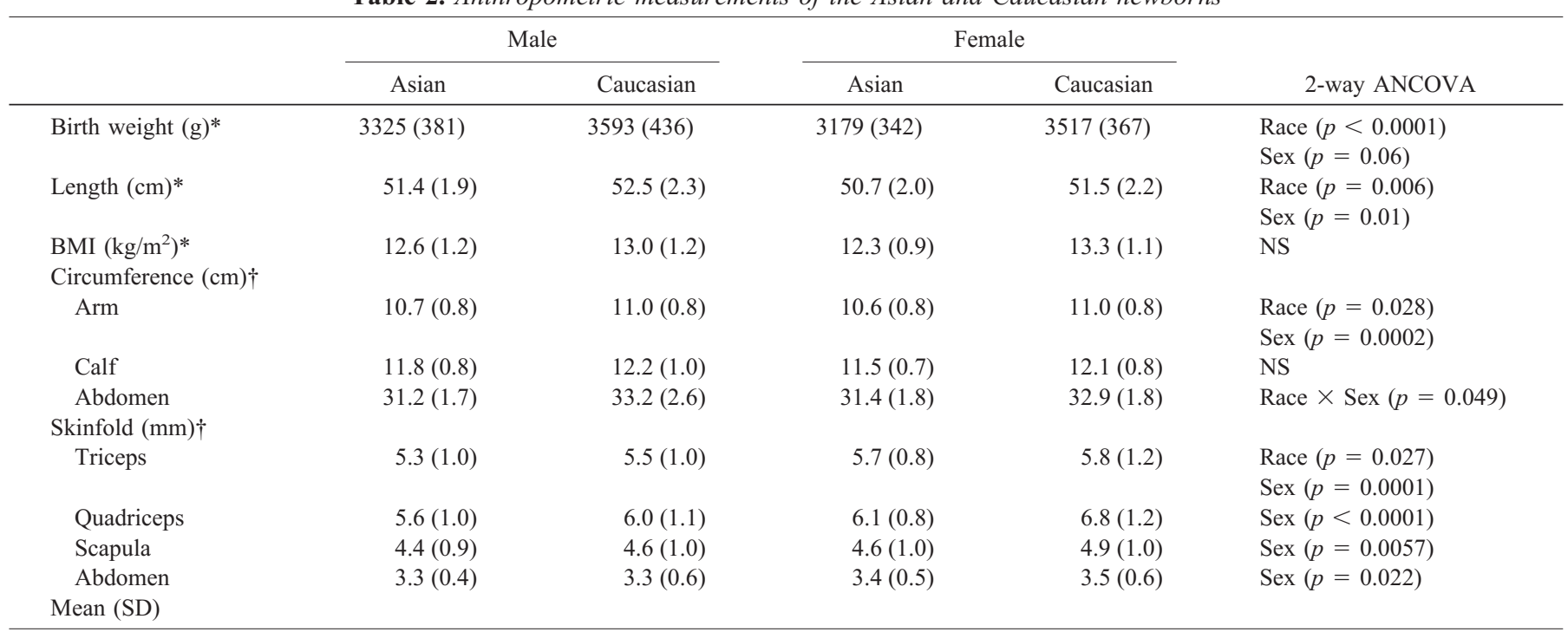

* Adjusted for parents' education.

$\uparrow$ Adjusted for birthweight. 
Table 3. Cord blood hormonal concentrations in male and female neonates from Asian and Caucasian groups

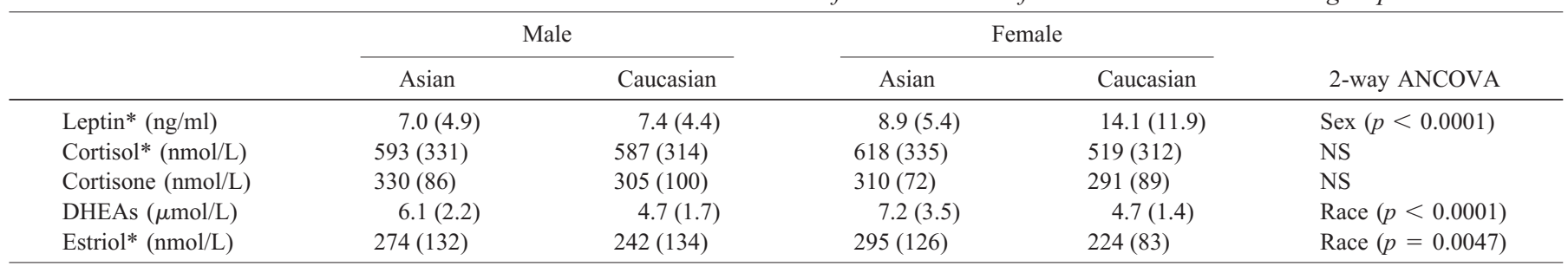

* Variable has been log-transformed for the analysis.

Mean (SD).

Conversion: Cortisol: $1 \mu \mathrm{g} / \mathrm{dl}=27.6 \mathrm{nmol} / 1$, Cortisone: $1 \mu \mathrm{g} / \mathrm{dl}=27.7 \mathrm{nmol} / 1$, DHEAs: $1 \mu \mathrm{g} / \mathrm{dl}=25.6 \mathrm{nmol} / 1$, Estriol: $1 \mu \mathrm{g} / \mathrm{dl}=34.7 \mathrm{nmol} / 1$.

Table 4. Correlation between cord leptin concentrations and anthropometric measures in each of the sub-groups of Asian and Caucasian neonates

\begin{tabular}{|c|c|c|c|c|}
\hline & \multicolumn{2}{|c|}{ Male } & \multicolumn{2}{|c|}{ Female } \\
\hline & Asian & Caucasian & Asian & Caucasian \\
\hline Birthweight & $0.51 \dagger$ & $0.48 \dagger$ & $0.47 *$ & $0.58 \ddagger$ \\
\hline Length & $0.36^{*}$ & 0.23 & 0.28 & 0.18 \\
\hline Body Mass Index & $0.33^{*}$ & $0.38 *$ & $0.33 *$ & $0.56 \ddagger$ \\
\hline \multicolumn{5}{|l|}{ Circumference } \\
\hline Arm & $0.51 \dagger$ & $0.62 \ddagger$ & $0.60 \%$ & $0.51 \dagger$ \\
\hline Calf & $0.46^{*}$ & $0.47 *$ & $0.39 *$ & $0.65 \div$ \\
\hline Abdomen & $0.32 *$ & $0.46^{*}$ & 0.29 & $0.45 *$ \\
\hline \multicolumn{5}{|l|}{ Skinfold } \\
\hline Triceps & $0.48 \dagger$ & $0.57 \ddagger$ & $0.50 \dagger$ & $0.49 \dagger$ \\
\hline Scapula & $0.53 \dagger$ & $0.42 *$ & $0.46^{*}$ & $0.54 \uparrow$ \\
\hline Quadriceps & $0.50 \dagger$ & $0.53 \dagger$ & $0.33 *$ & $0.50 \dagger$ \\
\hline Abdomen & $0.33^{*}$ & $0.34 *$ & $0.30 *$ & $0.38^{*}$ \\
\hline
\end{tabular}

$r$, Spearman coefficient of correlation.

$* p<0.05 ; \dagger p<0.001 ; \ddagger p<0.0001$.

of the regressions were not affected by gender in Asian newborns, they were significantly different in male and female Caucasian newborns ( $p=0.006$ and $p=0.002$ for birthweight and calf circumference, respectively) (Fig. 1).

Steroid hormone data. Plasma cortisol, cortisone (Table 3) and cortisol/cortisone ratios (data not shown) were similar in all four groups. In contrast, DHEAs concentrations were significantly higher in Asian male $(+30 \%)$ and female $(+54 \%)$ neonates compared with their Caucasian counterparts. The same trend was observed with oestriol although the difference was only significant in male newborns. There was no significant correlation between steroid hormones and leptin or any of the anthropometric measures.

\section{DISCUSSION}

In this study, we demonstrate for the first time that differences in body-fat distribution between Asians and Caucasians are already present at the time of birth and that the relationship between anthropometric measurements and umbilical cord leptin concentrations is affected by ethnicity and the sex of the infant.

Umbilical cord leptin could potentially originate from the fetal adipose tissue or from the placenta. Recent evidence suggests that the fetal adipocyte is the main determinant of circulating fetal leptin $(26,27)$. In contrast, while the placenta synthesizes leptin very actively (28), perfusion studies of human placentas have shown that the bulk of placental leptin is secreted into the maternal circulation (29).
In male newborns, absolute and relative (after normalization for birthweight) leptin concentrations are similar in Asians and Caucasians but the slope of the regression between leptin (after $\log$ transformation) and birthweight (and calf circumference) is different. Changes in birthweight of $500 \mathrm{~g}$ and $1 \mathrm{~kg}$ around the mean are associated with $30 \%$ and $70 \%$ differences in leptin concentrations, respectively, between Caucasian and Asian newborns. There is no significant difference in the relationship between leptin and other anthropometric markers. As calf circumference and birthweight are two of the best single anthropometric variables for the estimation of total body fat measured by total-body electrical conductivity in the neonate (30), our results suggest that we are indeed observing differences in the relationship between leptin and fat mass in these two groups. The cause of this difference is presently unclear. Conceptually, higher plasma leptin concentrations for a given body weight could be due to a greater number of adipocytes or to a higher quantity of leptin secreted per adipocyte. There are to our knowledge no data available on the characteristics of adipose tissue according to ethnicity.

In female neonates, there was no significant difference in the relationship between leptin and anthropometry in Asians and Caucasians. Whether a difference in the relationship between leptin and anthropometry between the sexes is also present later in life between Asians and Caucasians is not known but differences in body composition according to sex and ethnicity have been reported in Asian and Caucasian children by He et al. (19). For instance, extremity and gynecoid skinfold thickness are significantly greater in Caucasian compared with Asian girls, but not boys.

To our knowledge, there is only one other study comparing the growth of Asian and Caucasian infants. Tam et al. (31) compared the growth data of Chinese infants (obtained longitudinally during the first 2 years of life) to the NCHS reference data obtained mainly in Caucasian infants and children (32). Their results suggest that the BMIs of Chinese infants of both sexes increase more rapidly during the first seven to nine months of life compared with the NCHS data, mainly because of a more rapid weight gain. Whether this difference is due to genetic, nutritional or methodological factors (absence of a direct comparison between the two different groups) is unclear but these results suggest that fat accumulation during the first months of life may be different in Asian and Caucasian babies.

The comparison between the results we observe in newborns and published data in Asian and Caucasian adults is difficult. In addition to methodological differences, environmental factors 

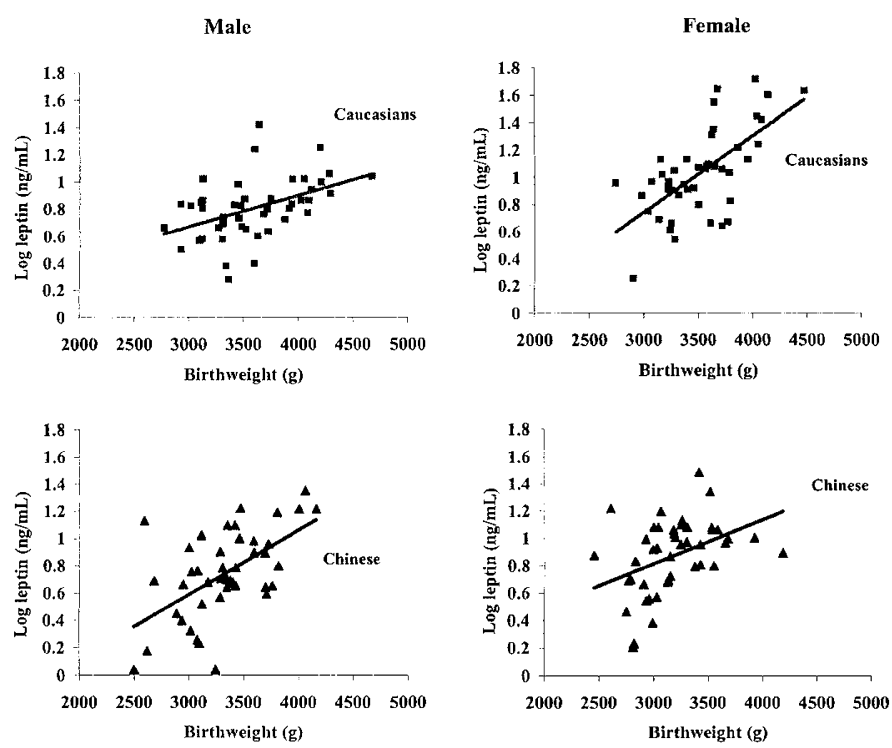

Figure 1. Relationship between cord log leptin concentration and birthweight in male (left panel) and female (right panel) newborns from Caucasian (upper panel) and Asian (lower panel) ethnicities. Male newborns: Caucasians: $y=$ $0.0002 x+0.07$; Asians: $y=0.0005 x-0.83$; Female newborns: Caucasians: $y=0.0006 x-0.94$; Asians: $y=0.0003 x-0.15$; where $y=\log$ leptin $(\mathrm{ng} / \mathrm{mL})$ and $x=$ birthweight $(\mathrm{g})$.

are likely to influence body composition. Wang et al. (17) compared several anthropometric measurements between Caucasian and Asian (mostly Chinese) adults aged 18 to 94 years living in New York. Weight, height and BMI were lower in Asian compared with Caucasians. Similar to the results found in our study, circumference measurements at various body sites and triceps skinfold measurements were similar or significantly lower by four to $6 \%$ in Asian subjects. In contrast, subscapular and abdominal skinfold measurements that were larger in Asian adult subjects are found to be similar in our neonates.

The cause of the difference in leptin regulation observed in our neonates could be of genetic or environmental origin. Le Stunff et al. (33) have shown in obese Caucasian girls that the relationship between fat mass and leptin could be affected by a common polymorphism of the leptin promoter. Whether this applies to our population of neonates is presently unknown.

Another hypothesis is that steroid hormones, known to stimulate leptin production by the adipocyte, could affect the relationship between leptin and anthropometry in Asian and Caucasian neonates. We selected cortisol, cortisone, oestriol and DHEAs because the concentrations of these hormones, that reflect mainly the function of the placenta and/or the fetal compartment (34-36), could potentially be different in Asian and Caucasian neonates. The productions of cortisol (37), DHEAs (37) and oestriol (38) are inhibited by phytoestrogens, a main component of Asian diets and the umbilical cord concentrations of oestriol are different in Asian and Caucasian subjects (39). Our results do not, however, suggest that leptin concentrations or anthropometric measures can be predicted by umbilical cord concentrations of these steroid hormones.

We paid particular attention to cortisol and cortisone levels for the following reasons. First, cortisol is known to stimulate leptin secretion both in vivo and in vitro $(22,23)$. Second, the activity of the placental enzyme $11 \beta$-hydroxysteroid dehydrogenase (EC 1.1.1.146) that actively converts cortisol to cortisone near term has been shown to be positively correlated to birth weight (40) although this was not confirmed by Rogerson et al. (41). Finally, a relative deficiency in $11 \beta$-hydroxysteroid dehydrogenase activity has been correlated with low birth weight, dyslipidemia, insulin resistance, and hypertension in adulthood $(42,43)$. In contrast to Maffeis et al. (9) and in agreement with Kirel et al. (44), we observed no correlation between cord cortisone or cortisol concentrations and birthweight.

Cord DHEAs concentrations specifically reflect the very active androgen production by the fetal adrenal (34) while cord oestriol concentrations reflect mainly the aromatization of $16 \alpha$ hydroxy DHEAs by the placenta (35). We found no significant correlation between DHEAs or oestriol and leptin concentrations. However, DHEAs levels were higher in male and female Asian neonates compared with their Caucasian counterparts. In agreement with published data (39), cord oestriol concentrations were also higher in Asian neonates although the difference was only significant in the female group.

\section{CONCLUSION}

In conclusion, we have demonstrated that differences based both on sex and ethnicity in the relationship between leptin and anthropometric markers are detectable at birth between two ethnic groups that are known to have different body compositions in childhood, adolescence and adulthood. We propose that these findings may reflect a different leptin set-point for a given fat mass at the hypothalamic level and may play a role in the differences in fat distribution observed later in life.

Acknowledgments. We thank the nurses of the delivery room at Children's and Women's Hospital for their assistance in the collection of the cord-blood samples and the technicians of the endocrine laboratory for processing the hormonal samples. The expert statistical help from Lee Shean Er, Statistician, British Columbia's Cardiac Registry at St-Paul's Hospital, Vancouver, is also gratefully acknowledged.

\section{REFERENCES}

1. Wauters M, Considine RV, Van Gaal LF 2000 Human leptin: from an adipocyte hormone to an endocrine mediator. Eur J Endocrinol 143:293-311

2. Schwartz MW, Woods SC, Porte D, Seeley RJ, Baskin DG 2000 Central nervous system control of food intake. Nature 404:661-671

3. Considine RV, Sinha MK, Heiman ML, Kriauciunas A, Stephens TW, Nyce MR, Ohannesian JP, Marco CC, McKee LJ, Bauer TL 1996 Serum immunoreactive-leptin concentrations in normal-weight and obese humans. N Engl J Med 334:292-295

4. Matsuda J, Yokota I, Iida M, Murakami T, Naito E, Ito M, Shima K, Kuroda Y 1997 Serum leptin concentration in cord blood: relationship to birth weight and gender. J Clin Endocrinol Metab 82:1642-1644

5. Schubring C, Kiess W, Englaro P, Rascher W, Dotsch J, Hanitsch S, Attanasio A, Blum WF 1997 Levels of leptin in maternal serum, amniotic fluid, and arterial and venous cord blood: relation to neonatal and placental weight. J Clin Endocrinol Metab $82: 1480-1483$

6. Sivan E, Lin WM, Homko CJ, Reece EA, Boden G 1997 Leptin is present in human cord blood. Diabetes 46:917-919

7. Hartmann BW, Wagenbichler P, Soregi G 1997 Maternal and umbilical-cord serum leptin concentrations in normal, full-term pregnancies. N Engl J Med 337:863

8. Shekhawat PS, Garland JS, Shivpuri C, Mick GJ, Sasidharan P, Pelz CJ, McCormick KL 1998 Neonatal cord blood leptin: its relationship to birth weight, body mass index, maternal diabetes, and steroids. Pediatr Res 43:338-343 
9. Maffeis C, Moghetti P, Vettor R, Lombardi AM, Vecchini S, Tato L 1999 Leptin concentration in newborn's cord blood: relationship to gender and growth-regulating hormones. Int J Obes Relat Metab Disord 23:943-947

10. Christou H, Connors JM, Ziotopoulou M, Hatzidakis V, Papathanassoglou E, Ringer SA, Mantzoros CS 2001 Cord blood leptin and insulin-like growth factor levels are independent predictors of fetal growth. J Clin Endocrinol Metab 86:935-938

11. Proietto J, Thorburn AW 1994 Animal models of obesity-theories of aetiology. Baillieres Clin Endocrinol Metab 8:509-525

12. Ravelli AC, van Der Meulen JH, Osmond C, Barker DJ, Bleker OP 1999 Obesity at the age of $50 \mathrm{y}$ in men and women exposed to famine prenatally. Am J Clin Nutr 70:811-816

13. Singhal A, Farooqi IS, O'Rahilly S, Cole TJ, Fewtrell M, Lucas A 2002 Early nutrition and leptin concentrations in later life. Am J Clin Nutr 75:993-999

14. Masuzaki H, Ogawa Y, Isse N, Satoh N, Okazaki T, Shigemoto M, Mori K, Tamura N, Hosoda K, Yoshimasa Y 1995 Human obese gene expression. Adipocyte-specific expression and regional differences in the adipose tissue. Diabetes 44:855-858

15. Montague CT, Prins JB, Sanders L, Zhang J, Sewter CP, Digby J, Byrne CD, O'Rahilly S 1998 Depot-related gene expression in human subcutaneous and omental adipocytes. Diabetes 47:1384-1391

16. Deurenberg-Yap M, Schmidt G, van Staveren WA, Deurenberg P 2000 The paradox of low body mass index and high body fat percentage among Chinese, Malays and Indians in Singapore. Int J Obes Relat Metab Disord 24:1011-1017

17. Wang J, Thornton JC, Russell M, Burastero S, Heymsfield S, Pierson RN 1994 Asians have lower body mass index (BMI) but higher percent body fat than do whites: comparisons of anthropometric measurements. Am J Clin Nutr 60:23-28

18. Malina RM, Huang YC, Brown KH 1995 Subcutaneous adipose tissue distribution in adolescent girls of four ethnic groups. Int J Obes Relat Metab Disord 19:793-797

19. He Q, Horlick M, Thornton J, Wang J, Pierson RN, Heshka S, Gallagher D 2002 Sex and race differences in fat distribution among Asian, African-American, and Caucasian prepubertal children. J Clin Endocrinol Metab 87:2164-2170

20. McConway MG, Johnson D, Kelly A, Griffin D, Smith J, Wallace AM 2000 Differences in circulating concentrations of total, free and bound leptin related to gender and body composition in humans. Ann Clin Biochem 37:717-723

21. Considine RV 2001 Regulation of leptin production. Rev Endocr Metab Dis 2:357-

22. Wabitsh M, Jensen PB, Blum WF, Christoffersen CT, Englaro P, Heinze E, Rasche W, Teller W, Tornqvist H, Hauner H 1996 Insulin and cortisol promote leptin production in cultured human fat cells. Diabetes 45:1435-1438

23. Askari H, Liu J, Dagogo-Jack S 2000 Hormonal regulation of human leptin in vivo: effects of hydrocortisone and insulin. Int J Obes Relat Metab Disord 24:1254-1259

24. Duncan GJ, Daly MC, McDonough P, Williams DR 2002 Optimal indicators of socioeconomic status for health research. Am J Public Health 92:1151-1157

25. Weber B, Lewicka S, Deuschle M, Colla M, Vecsei P, Heuser I 2000 Increased diurnal plasma concentrations of cortisone in depressed patients. J Clin Endocrino Metab 85:1133-1136

26. Lepercq J, Challier JC, Guerre-Millo M, Cauzac M, Vidal H, Hauguel-de Mouzon S 2001 Prenatal leptin production: evidence that fetal adipose tissue produces leptin. J Clin Endocrinol Metab 86:2409-2413

27. Jaquet D, Leger J, Levy-Marchal C, Oury JF, Czernichow P 1998 Ontogeny of leptin in human fetuses and newborns: effect of intrauterine growth retardation on serum leptin concentrations. J Clin Endocrinol Metab 83:1243-1246
28. Ashworth CJ, Hoggard N, Thomas L, Mercer JG. Wallace JM. Lea RG 2000 Placental leptin. Rev Reprod 5:18-24

29. Hoggard N, Crabtree J, Allstaff S, Abramovich DR, Haggarty P 2001 Leptin secretion to both the maternal and fetal circulation in the ex vivo perfused human term placenta. Placenta22: $347-352$

30. de Bruin NC, van Velthoven KAM, Stijnen T, Juttmann RE, Degenhart HJ, Visser HKA 2051995 Body fat and fat-free mass in infants: new and classic anthropometric indexes and prediction equations compared with total-body electrical conductivity. Am J Clin Nutr 61:1195-1205

31. Tam SYM, Karlberg JPE, Kwan EYW, Tsang AMC, Sheng THP, He Q, Low LCK 1999 Body mass index is different in normal Chinese and Caucasian infants. J Pediatr Endocrinol Metab 12:507-517

32. Hamill PVV, Drizd TA, Johnson CL, Reed RB, Roche AF 1977 NCHS growth curves for children, birth-18 years, United States. Hyattsville, MD: National Center for Health Statistics, DHEW Publication Number (PHS)78-1650

33. Le Stunff C, Le Bihan C, Schork NJ, Bougneres P 2000 A common promoter variant of the leptin gene is associated with changes in the relationship between serum leptin and fat mass in obese girls. Diabetes 49:2196-2200

34. Speroff L, Glass RH, Kase NG 1999 Clinical Gynecologic Endocrinology and Infertility, 6th Ed. Lippincott Williams \& Wilkins, Baltimore, pp 275-335

35. Perry L, Hickson R, Obiekwe BC, Chard T 1986 Maternal oestriol levels reflect placental function rather than fetal function. Acta Endocrinol 111:563-566

36. Parker CR, Leveno K, Carr BR, Hauth J, MacDonald PC 1982 Umbilical cord plasma levels of dehydroepiandrosterone sulfate during human gestation. J Clin Endocrinol Metab 54:1216-1220

37. Mesiano S, Katz SL, Lee JY, Jaffe RB 1999 Phytoestrogens alter adrenocortical function: genistein and daidzein suppress glucocorticoid and stimulate androgen production by cultured adrenal cortical cells. J Clin Endocrinol Metab 84:2443-2448

38. Kao YC, Zhou C, Sherman M, Laughton CA, Chen S 1998 Molecular basis of the inhibition of human aromatase (estrogen synthetase) by flavone and isoflavone phytoestrogens: A site-directed mutagenesis study. Environ Health Perspect 106:85-92

39. O’Brien JE, Dvorin E, Drugan A, Johnson MP, Yaron Y, Evans MI 1997 Raceethnicity-specific variation in multiple-marker biochemical screening: alphafetoprotein, hCG, and estriol. Obstet Gynecol 89:355-358

40. Stewart PM, Rogerson FM, Mason JI 1995 Type 211 beta-hydroxysteroid dehydrogenase messenger ribonucleic acid and activity in human placenta and fetal membranes: its relationship to birth weight and putative role in fetal adrenal steroidogenesis. J Clin Endocrinol Metab 80:885-890

41. Rogerson FM, Kayes KM, White PC 1997 Variation in placental type 211 betahydroxysteroid dehydrogenase activity is not related to birth weight or placental weight. Mol Cell Endocrinol 128:103-109

42. Shams M, Kilby MD, Somerset DA, Howie AJ, Gupta A, Wood PJ, Afnan M, Stewart PM 1998 11Beta-hydroxysteroid dehydrogenase type 2 in human pregnancy and reduced expression in intrauterine growth restriction. Hum Reprod 13:799-804

43. Seckl JR, Cleasby M, Nyirenda MJ 2000 Glucocorticoids, $11 \beta$-hydroxysteroid dehydrogenase, and fetal programming Kidney Int 57:1412-1417

44. Kirel B, Tekin N, Tekin B, Kilic FS, Dogruel N, Aydogdu SD 2000 Cord blood leptin levels: relationship to body weight, body mass index, sex and insulin and cortisol levels of maternal-newborn pairs at delivery. J Pediatr Endocrinol Metab 13:71-77 